\title{
Current Situation and Countermeasures of Enshi's Agricultural Economic Development Based on information technology
}

\author{
Quanhong Liu*1,a, Hu Chen ${ }^{2, b}$ \\ ${ }^{1}$ School of Business, Jianghan University, Wuhan, China \\ ${ }^{2}$ School of Business, Jianghan University, Wuhan, China
}

\begin{abstract}
Agricultural economic development has great significance of China to win the campaign against poverty, and the intelligent agriculture based on information technology is the cornerstone of rural revitalization strategy. This paper takes Enshi Tujia and Miao Autonomous Prefecture as an example, discusses the advantages and disadvantages of its current agricultural economic development, and puts forward some countermeasures and suggestions based on the utilization of information technology.
\end{abstract}

\section{Introduction}

Enshi Tujia and Miao Autonomous Prefecture is an autonomous prefecture in Hubei province, belonging to the typical 'Old, young, frontier and poor' povertystricken area. In the campaign of poverty alleviation led by the CPC Central Committee in April 2020, they have achieved comprehensive poverty alleviation. In the process of poverty alleviation, agricultural operation income plays an important role. The total output value of agriculture, forestry, animal husbandry and fishery in Enshi reached 32.914 billion yuan in 2019, accounting for 28.38 percent of the regional GDP.

At present, China is facing a downward economic situation. The COVID-19 epidemic has affected the steady growth of agricultural production and farmers' income. The fight against poverty has just been completed. It is easy for rural people to get rid of poverty, but they need to further consolidate their base, only by avoiding falling into poverty and maintaining the economic development trend of agricultural and rural areas, we can further promote the revitalization of rural areas and build a better and happier life.

\section{The Significance of Agriculture Economic Development}

"Issues concerning agriculture, rural areas and farmers" is a difficult problem that must be overcome in the process of realizing an all-round well-off society. The leadership of the CPC Central Committee has stressed many times that it is necessary to do a good job in the field of "agriculture, rural areas and farmers" and "take the overall initiative to improve agriculture, rural areas and farmers". The steady development of agriculture, rural areas and farmers is an important guarantee for completing the building of a moderately prosperous society in all respects.
Agriculture plays the role of "Ballast" and "Stabilizer" in the development of economy and society. The 2020 government work report pointed out that China's economy is facing downward pressure, in addition to the international environment is becoming more complex, and the risk challenges from the domestic and abroad are significantly higher. The more complicated the economic development situation is, the more important it is to stabilize the development of agriculture.

Building a new socialist countryside is an important measure to achieve overall well-off. At the present stage, rural development is relatively backward, the farmers' income is relatively low, and the rural infrastructure construction is weak. Developing a good rural economy, improving the living conditions of farmers, building a better and happier home for farmers, and making their lives more prosperous can ensure that all the people share in the fruits of economic development, promoting the integrated development of urban and rural economies, narrowing the income gap between urban and rural areas.

The famers' issue is the core of the "Issues concerning agriculture, rural areas and farmers". The increase in farmers' income is directly related to the quality of a welloff society. our country has just completed the important mission of eradicating poverty, agricultural business income also accounts for a significant portion. The steady increase of farmers' income can fully arouse the enthusiasm and initiative of farmers and turn their yearning for a better life into the driving force of economic construction.

\footnotetext{
a*e-mail: qhliu@jhun.edu.cn

be-mail: 1120673586@qq.com
} 


\section{Current Advantages of Enshi's Agricultural Economic Development}

\subsection{Abundant Natural Resources and Vast Market for Agriculture with Distinctive Features}

Functional agriculture is a trend in the future, and agricultural products rich in micronutrient and nutrients can make up for the daily needs of the human body. Selenium is one of the 14 essential trace elements in human body, but it can't be naturally synthesized in the body and must be supplemented through external means, the safest of which is a dietary supplement. The Enshi area is recognized as the selenium capital of the world. There are world-class independent selenium deposits buried underground, which has formed a huge selenium-rich biosphere with rich biodiversity and a wide variety of selenium-rich agricultural products. The climate is excellent, warm, and rainy, and four distinct seasons have created a series of characteristic selenium product industries such as Enshi small potatoes, Enshi Yulu tea, and Tujia black pork [1]. The production of selenium rich agricultural products is no different from ordinary agricultural products in terms of production methods inputs of production materials, but it has a higher economic value. At present, the selenium-based agricultural technology in Enshi is basically mature, which can lengthen the industrial chain and has a greater industry-driven effect, forming the pattern of combining the planting industry, breeding industry, processing industry, logistics industry and tourism, and the linkage of various industries, promoting regional economic development.

\subsection{State Policy Support}

Enshi Tujia and Miao Autonomous Prefecture is a typical poor region, to which the state has paid great attention to this. The steady implementation of the policy incline of the western development strategy and the poverty alleviation strategy has brought a lot of talent support and financial input to Enshi Prefecture. The cadres who help the poor go to the villages to teach the advanced knowledge of agriculture and help the development of agricultural industrialization. In the agricultural support of the Enshi area, we should insist on cultivating one or two pillar industries in one county and city, and construct the industrial layout of "One township, one industry, one village, one product". We will strengthen the construction of high-standard characteristic industrial bases, and promote the development of agricultural and sideline products towards quality and scale. Support should be given to new agricultural economic entities, give full play to the leading role, guide farmers to create agricultural products brands, enhance the popularity of products, and vigorously strengthen the construction of regional comprehensive wholesale markets to enrich the marketing channels of agricultural and sideline products.

\subsection{Complete Conditions for the Modernization of Information Technology}

Information construction is the key to building a new socialist countryside, network optical fiber basically in rural areas to achieve comprehensive coverage. Almost all rural households have smart phones and computers. The Internet has achieved full penetration, making network information communication more convenient and efficient. The relevant agricultural support policies issued by the state or the government can be carried out peer-to-peer dissemination for the first time, saving time, improving efficiency, and guaranteeing in timeliness and accuracy[2] Secondly, agricultural science and technology is widely spread on the network, agricultural practitioners can download and learn by themselves, the famers can learn the development of new industrial technology in time, learn from experience and improve their knowledge level. Finally, it breaks the information gap between consumers and producers, the real market demand and supply are shown to promote the balance between supply, production, and marketing.

\section{Current Weaknesses of Enshi's Agricultural Economic Development}

\subsection{Lagging behind in Development}

Affected by history and natural conditions and other factors, Enshi region has been in poverty for a long time and its agricultural infrastructure is relatively weak. As a result of economic isolation, farmers' ideological awareness is more traditional. Many places still adopt traditional farming methods. The traditional agricultural development methods are crude. The emphasis is on the consumption of human resources. It is difficult to guarantee the quality of agricultural products. The mode of production and management is still small-scale, decentralized, difficult to form scale effect, the degree of industrialization of agricultural products is not high. When the special agriculture is popularized, the corresponding infrastructure is often lacking, and the farmers lack enough economic strength to participate, which leads to the poor development of the special agriculture. In addition, the Enshi region locates in the Wuling Mountains, the distribution of cultivated land is decentralized and fragmented. Coupled with the limitations of the level of agricultural science and technology, it is difficult to construct farmland water conservancy and irrigation facilities. Overall, the area of the characteristic industry base in Enshi has taken shape, but the level of agricultural product reprocessing technology is low, the agricultural industry chain is not perfect, and the new type of agricultural management main body has failed to get a good driving effect.

\subsection{Insufficient Allocation of Elements}

Under the accelerated urbanization process, there is a huge income gap between urban and rural areas. Farmers face the trap of high consumption while their incomes are low. 
The prices of medical care and education have converged with urban residents, increasing the cost of living. The annual income increase is slow; the young labor force is out of large numbers, leaving a bunch of old and weak women and children in the countryside, which also produces a series of education problems for left-behind children and support for the elderly.

Farmers' income is unstable and they lack the willingness to take out loans themselves. The nature of agricultural production determines that it is less riskresistant and more affected by natural disasters and market factors. Due to the weak economic foundation, it is difficult for individual farmers to meet the guarantee requirements of formal financial institutions with their own assets [3]. Dare not to finance and can't finance as an important reason for the lack of agricultural funds.

Existing agricultural technical personnel at the grassroots level of aging, their knowledge structure is out of date, their understanding of agriculture remains on the traditional concept, and their understanding of modern information agriculture and characteristic ecological agriculture is not in place, the young people engaged in agricultural science and technology promotion is not high, the number of college students participating in the construction of returning to their hometowns is low, there is a lack of young agricultural technicians at the grassroots level.

\subsection{The demand of agricultural information service is strong}

\begin{tabular}{|c|c|c|c|c|}
\hline $69.10 \%$ & $71.00 \%$ & $74.60 \%$ & $76.50 \%$ & $79.80 \%$ \\
\hline $33.10 \%$ & $35.40 \%$ & $38.40 \%$ & $46.20 \%$ & $\begin{array}{r}55.90 \% \\
\times\end{array}$ \\
\hline 2016.12 & 2017.12 & 2018.12 & 2019.12 & 2020.12 \\
\hline \multicolumn{5}{|c|}{-Internet penetration rate in urban areas } \\
\hline \multicolumn{5}{|c|}{$\ldots$ Internet penetration rate in rural areas } \\
\hline
\end{tabular}

Figure 1. Recent Internet penetration rate in China

By December 2020, the Internet penetration rate in urban areas was 79.8 percent, 3.3 percentage points higher than in March 2020, and the Internet penetration rate in rural areas was 55.9 percent, 9.7 percentage points higher than in March 2020 (Fig. 1). The further popularization of the Internet has promoted the development of rural information technology. Agricultural information service plays an important role in the development of agricultural informatization, which runs through the whole process from production to sales. Agricultural resources in Enshi are scattered, the construction of agricultural information service platform is not perfect, and the lack of agricultural informatization talents makes it difficult to release agricultural information in time [4]. The lag of information affects agricultural development.

\section{Countermeasures}

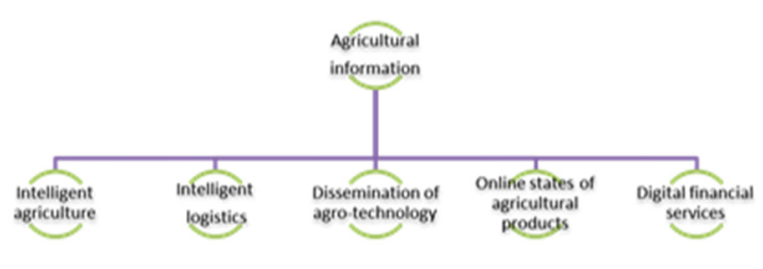

Figure 2. The Countermeasures of the Enshi's Agricultural Economic Development

\subsection{Improving Agricultural Infrastructure and Developing "Intelligent Agriculture"}

"Intelligent agriculture" is the organic combination of highly developed information technology and intelligent equipment with traditional agriculture (Fig. 2). The Enshi Tujia and Miao Autonomous Prefecture government can set up a selenium product intelligence industrial park according to its own regional characteristics, rely on the platform of information, and uniformly release product information on the network, below the line then trains and guides the farmer to participate in the centralized industry management with the cooperation form positively. Using the Internet of Things (IoT) technology, they built a sophisticated irrigation control and crop feedback system [5]. People can monitor crops and soil in real time through the equipment and adjust the temperature intelligently. The whole process of livestock breeding and aquaculture feeding can be controlled by computer, and the whole production chain can be managed by accurately calculating the time of release or salability. In addition, agricultural parks can collectively invite agricultural scholars or experts to popularize agricultural science knowledge, and in the sales process, agricultural parks can also cooperate with e-commerce platforms to get orders in advance during the production process, instead of lagging behind the market. The industrial park, farmers, processors, e-commerce platform and market are closely linked together through data. Building the industrial park platform requires great capital investment and related technical training, and the core is to build a big agricultural data center. Firstly, the construction of telecommunication network in rural areas should be guaranteed to achieve full network coverage and combine Internet of Things, big data, and artificial intelligence technologies with current industries. Secondly, we should improve the construction of farmland water conservancy and other infrastructure to meet the demand of water irrigation and promote the construction of high-standard farmland.

\subsection{Training Agricultural Technicians and Attaching Importance to Local Practical Talents}

The government should formulate a reasonable talent subsidy policy, attach importance to talent training, treat 
urban talent as well as rural talent equally, provide interest-free loans and special funds to support, encourage talent innovation and entrepreneurship, and attract talent to stay. Efforts to dig out a field of rural practical talents set up a model of practical talents to promote technology. The experience of practical talents is applicable to farmers with low knowledge level, and can be used for reference. In addition, it is necessary to strengthen the construction of talent feelings, cultivate the sense of mission and honor for the rural areas, to retain the outstanding talents in the rural areas, to give full play to their intelligence, to build a brick for agricultural construction.

The allocation of agricultural technical personnel can't be completed by the government system alone, but should form a professional and industrialized training mode of agricultural technical personnel, combining on-line and off-line technical guidance. The off-line government takes the lead in cooperation with enterprises, constructs the agricultural technology training platform, establishes specialized agricultural technology personnel training troops, and organizes the personnel to carry on fixed-point training. The trainees are assigned to different regions to form small-scale agricultural consultation platforms specializing in agricultural consultation. The salaries of knowledge-sharing personnel are financed by local finance, and professional agricultural technical support is provided to farmers in need for a small fee or free of charge.

\subsection{Developing Rural Logistics to Break the Supply and Marketing Difficulties}

The development of modern logistics technology can reduce the loss of agricultural products in the process of transportation to a great extent. The application of Internet technology to rural logistics can improve the intelligence level of rural logistics in China and make it serve more efficiently while reducing costs. In particular, the use of big data and cloud computing can make the relationship between various processes of rural logistics closer [6]. The government can support the development of rural logistics enterprises through funds, encourage villagers to raise funds to purchase refrigeration and fresh-keeping equipment, carry out rural logistics training courses, and train a few practical talents familiar with logistics. Strengthen financial support for rural logistics, support the construction of logistics by local enterprises in rural areas and the development of third-party logistics, and fund the construction of large-scale cold-chain facilities for storage and preservation of agricultural products. In the mode of operation and management, we can learn from mature logistics enterprises, in the transport, packaging, processing, warehousing processes strictly follow the relevant national logistics standards. At the same time, the construction of basic roads in rural areas should be strengthened to facilitate the use of containers and large refrigerated trucks.

\subsection{Improving the Marketing Pattern of Agricultural Products and Expanding their Market Scope}

In recent years, the tendency of online shopping has shifted from traditional commodities to high-quality agricultural products. Online marketing has become a new marketing channel for agricultural products, while the interaction between agricultural products and e-commerce platforms in Enshi is still not close, and the overall visibility on e-commerce platforms is poor. The popularity of the products is mainly confined to the provinces and surrounding provinces. The main sales market is still the provincial market. With the help of platforms such as rural Taobao, JD.com and Pinduoduo, the Enshi government subsidized the promotion platform by issuing consumer vouchers and offered preferential prices for agricultural products, so that more people could get to know about them. With the help of this kind of activity, we will make a centralized display of regional high-quality agricultural products. Compared with the offline agricultural products fair, it is cheaper to release product information on the Internet, and the audience is also spread all over the country, helping the information of high-quality agricultural products to the outside world. Some farmers are not sensitive to the application of the Internet; lack of understanding also can not start. The government could set up a live training team to create a rural "Commoner" who could teach classes, share product introductions, sales tips, make-up and video clips, using live broadcast mode to connect small farmers with internet market, to overcome the asymmetry of information, to realize the "Visualization" and accurate marketing of agricultural products, to break the cognitive barriers between agricultural products and consumers, to realize the commercial value of agricultural products. Let agricultural products sell at a reasonable price, not only let consumers be satisfied, but also to achieve the expectations of farmers' income.

\subsection{Innovating Financial Services to Boost the Industrialization of Agriculture}

We will improve the rural financial service system, guide the Agricultural Development Bank, and provide preferential Rural Credit Cooperatives services to farmers. Increase the capital investment of financial funds to agriculture, rural areas and farmers, and construct policy finance [7]. The Central Committee of the Communist Party of China (CPC) proposed in the opinions on the implementation of the rural revitalization strategy that more financial resources should be allocated to the weak links and key areas in rural areas. The establishment of a special policy-oriented financial institution is a good use of the long-term poverty in the Enshi region, where some farmers live in difficulty and lack the conditions for agricultural loans. Policy-oriented finance can effectively guide and promote the integrated development of rural industries. In recent years, policy banks have used satellite remote sensing technology to promote the development of digital finance and facilitate loans for farmers. The principle is to round the farmers' land by mobile map. 
After identifying their land, the Bank will identify the crop area and crop type of land through satellite images, and estimate the benefits and value through risk control models in order to provide farmers with loan amounts and reasonable repayment periods. Through policy-oriented finance, the government carries out the construction of regional layout plans such as agricultural science and Technology Parks and Farmers' pioneering parks, supporting the construction of high-standard farmland and high-yield and high-efficiency agricultural production bases, and promoting the upgrading of agricultural characteristic industries.

\section{Conclusion}

Economic development should be comprehensive. The rapid growth of industry and service industry, and the sluggish growth of agriculture will hinder the overall process. " Issues concerning agriculture, rural areas and farmers " is directly related to the construction of socialist modernization, related to the overall national quality of the promotion. We should be noticed that the "three rural issues" is a historical issue, which cannot be solved overnight or overnight, but a systematic and complex, long-term and arduous project, which needs to be gradually laid a solid foundation and completed step by step. We should proceed from the interests of the peasant masses, start from the actual situation in rural areas, and start from the problems to be solved in agricultural development to accelerate the development of rural industries and promote the overall progress of rural areas. With prosperous agriculture, beautiful countryside and rich farmers, a colorful exhibition on agriculture, rural areas and farmers is bound to make the country prosperous and strong.

\section{References}

1. Y. Chen, "Research on the development path of agricultural economy transformation in the poor areas under the new situation: based on the empirical analysis of Enshi Tujia and Miao Autonomous Prefecture, Hubei Province", Journal of Economic Research, 2020, (28): 18-19.

2. W. Hou, J. Zheng, “Accelerate agricultural informatization construction, promote agricultural modernization development", New Agriculture, 2020 (23): 77.

3. H. Min, "Thoughts on the construction of modern rural financial service system in China", Economic Research Reference, 2014, (17): 29-30; 36.

4. F. Wu, L. Cao, J. Zhao, et al., "Study on the construction of the development demand of agricultural informatization", Modern agriculture, 2020,(9): 45-46.

5. S. Yang, "Application of internet of things technology in agricultural informatization construction", Southern Agricultural Machinery, 2020, (14): 60-61.
6. Y. Yang, "Research on supply chain of modern rural logistics in China", China Market, 2020, (33): 158; 164.

7. H. Li, "New era rural financial service system innovation research", Friends of Accountants, 2020, (23): 41-45. 